\title{
Michael Korthaus
}

\section{Kreuzestheologie}

\section{Geschichte und Gehalt eines Programmbegriffs in der evangelischen Theologie}

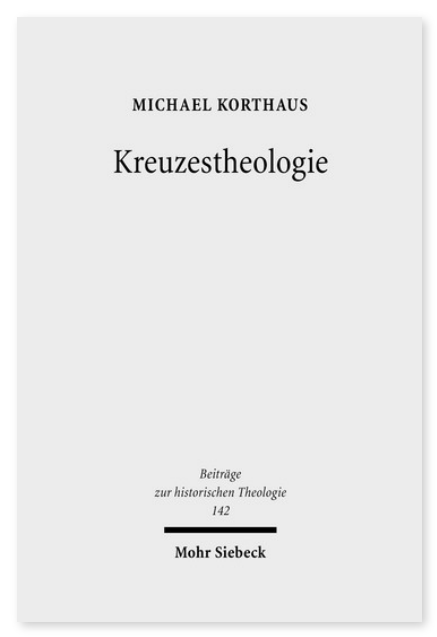

2007. XII, 431 Seiten. BHTh 142

SBN 978-3-16-151052-6

DOI 10.1628/978-3-16-151052-6

eBook PDF 139,00€

ISBN 978-3-16-149337-9

Leinen $139,00 €$
"Kreuzestheologie« ist ein wichtiges Schlagwort in evangelischer Kirche und Theologie. Mit seiner Verwendung verbindet sich durchweg der hohe Anspruch, christologische Grundeinsichten der paulinischen Theologie in der Perspektive v.a. des jungen Luther zu gegenwartsrelevanter Geltung zu bringen. »Kreuzestheologie« wird so stets als neutestamentlich ausgewiesene Reformationstheologie für die jeweilige Gegenwart ins Spiel gebracht. Dieser Anspruch legt die Vermutung nahe, bei 'der' Kreuzestheologie handele es sich um einen Denkweg mit klaren historischen Anknüpfungspunkten und einheitlichem systematischem Profil. Die theologische Wirklichkeit sieht allerdings ganz anders aus: Tatsächlich gibt es eine ganze Reihe z.T. sehr unterschiedlich konzipierter Kreuzestheologien. Michael Korthaus zeigt, dass das, was heute unter »Kreuzestheologie« im Sinne eines spezifischen theologischen Denkansatzes verstanden wird, weniger ein im historischen Sinne genuin reformatorisches, sondern ein durchaus modernes Konzept ist, das aus der Lutherforschung der zwanziger Jahre des vorigen Jahrhunderts in die Systematische Theologie eingewandert ist und hier im Dienste des Bemühens steht, protestantische Gegenwartstheologie ausdrücklich biblisch-reformatorisch zu profilieren. Der Autor stellt zunächst in theologiegeschichtlicher Perspektive so unterschiedliche Kreuzestheologien wie die von Kähler, Iwand, Barth, Ebeling, Moltmann, Jüngel u.a. dar. Der zweite Teil des Buches leistet in systematisch-theologischer Perspektive einen Beitrag zu einer gegenwärtig verantworteten Kreuzestheologie.

Michael Korthaus Geboren 1967; Studium der evangelischen Theologie in Bethel, Marburg, Rom und Münster; 1999 Promotion; 2001 Ordination; 2005 Habilitation; Pfarrer in der Thomasgemeinde in Münster, zugleich Privatdozent an der Ev.Theol. Fakultät der WWU Münster.

Jetzt bestellen:

https://mohrsiebeck.com/buch/kreuzestheologie-9783161510526?no_cache=1

order@mohrsiebeck.com

Telefon: +49 (0)7071-923-17

Telefax: $+49(0) 7071-51104$ 